\title{
Effect of Ginsenoside Rh-2 via Activation of Caspase-3 and Bcl-2-Insensitive Pathway in Ovarian Cancer Cells
}

\author{
Jin Hee KIM ${ }^{1}$, Jae-Sun CHOI ${ }^{2}$ \\ ${ }^{1}$ School of Life Sciences and Biotechnology, Korea University, Seoul, Korea, ${ }^{2}$ Department of \\ Biomedical Laboratory Science, Far East University, Eumseong, Korea
}

Received April 27, 2016

Accepted July 22, 2016

\section{Summary}

Ginsenoside has been reported to have therapeutic effects for some types of cancer, but its effect on ovarian cancer cells has not been evaluated. In this study, we monitored the effects of ginsenoside-Rh2 (Rh2) on the inhibition of cell proliferation and the apoptotic process in the ovarian cancer cell line SKOV3 using an MTT assay and TUNEL assay. We found that Rh2 inhibited cell proliferation and significantly induced apoptosis. We confirmed the apoptotic effects of Rh2 using western blot analysis of apoptosis-related proteins. Specifically, the levels of cleaved poly ADP ribose polymerase (PARP) and cleaved caspase-3 significantly increased in SKOV3 cells treated with $\mathrm{Rh} 2$. Therefore, Rh2 clearly suppressed the growth of SKOV3 cells in vitro, which was associated with induction of the apoptosis pathway. Moreover, the migration assay showed that Rh2 inhibited the invasive ability of SKOV3 cells. Taken together, our results suggest that Rh2 has anticancer effects in SKOV3 cells through inhibition of cell proliferation and induction of apoptosis. Considering the therapeutic potential of Rh2, more studies should be carried out to facilitate the future application of this natural product as a potential anti-cancer agent.

\section{Key words}

Ginsenoside-Rh2 • Ovarian cancer cells • Apoptosis • Epithelialmesenchymal transition

\section{Corresponding author}

J.-S. Choi, Department Biomedical Laboratory Science, Far East University, 76-32 Daehakgil, Gamgok-myeon, Eumseong-gun, Chungbuk-Do, 369-700, Korea. Fax: +82-43-880-3876. E-mail: jaenny123@gmail.com

\section{Introduction}

Ovarian cancer is the most lethal gynecologic malignancy and exists predominantly in the form of epithelial ovarian cancer (Cho and Shih 2009, Swisher et al. 2012). Natural products are a valuable resource for the development of anticancer drugs and recent studies have revealed the anti-cancer properties of several types of natural products traditionally used as medicines (da Rocha and Lopes 2001, Mann 2002). One of the main mechanisms by which these products exert their therapeutic effects is via induction of apoptosis in cancer cells.

Apoptosis is a type of programmed cell death involving the activation of caspases through either an intrinsic mitochondria-dependent or an extrinsic mitochondria-independent cellular pathway (Salvesen and Dixit 1997, Fulda and Debatin 2006). Decreased cell volume is a typical morphological phenotype of apoptotic cells (Jacobson et al. 1997, Nagat 1997, Taatjes et al. 2008). Apoptosis involves a cascade of molecular changes, including morphologically changes, chromatin condensation, and DNA fragmentation (Chung et al. 2007, Sanjiv et al. 2012). Abnormal regulation of apoptosis leads to many human disorders, including cancers. Therefore, targeting and exploiting the mechanism of apoptosis is an important strategy for the treatment of cancer (Kelloff et al. 2000, Sun et al. 2007). Caspase activation is often regulated by various cellular factors, including members of the Bcl-2 family. The caspase cascade is a key pathway in apoptotic signal transduction, and its components can be divided into two subfamilies: upstream initiator caspases and downstream 
effector caspases, which directly induce the final events in apoptosis (Lavrik et al. 2005, Lamkanfi et al. 2007, $\mathrm{Lu}$ et al. 2012). A central component of the programmed cell death process via the caspase cascade is apoptosis proteinase-activating factor-1 (Apaf-1) complex formation, and heterodimerization of $\mathrm{Bcl}-2$ family proteins (Green and Reed 1998, Liu et al. 1996), which control the activation of caspases (Vaux and Korsmeyer 1999). Bcl-2-related proteins fall into two groups that either repress or promote apoptosis. During apoptosis, translocation of cytochrome $\mathrm{c}$ to the cytosol promotes Apaf-1 complex formation, which initially results in activation of caspase- 9 followed by the activation of other caspases. Eventually, the caspases cleave the cellular proteins resulting in programmed cell death. Poly ADP ribose polymerase (PARP) is a substrate for caspases and is cleaved into fragments during apoptosis fragments.

Ginseng (Panax ginseng) has a variety of pharmacological and therapeutic applications, and has thus become one of the most popular traditional Chinese medicines. Ginsenosides are considered as the main bioactive components of herbal medicines derived from ginseng, which are triterpene saponins. In particular, the ginsenosides have been reported to have anti-cancer, antiinflammatory, antioxidative, and vasorelaxing properties (Jang et al. 2014, Luo et al. 2008, Wang et al. 2007, Wang et al. 2008). Nevertheless, the exact molecular mechanism of the anti-cancer effect of the ginsenosides $\mathrm{Rh} 2$ remains unclear.

In this study, we investigated the effects of Rh2 on inhibition of cell proliferation and the apoptotic process in ovarian cancer in vitro.

\section{Materials and Methods}

\section{Cell line and reagent}

The cells used in this study were human ovarian adenocarcinoma cells SKOV3 (American Type Culture Collection, Rockville, MD, USA). The cells were cultured in a mixture of RPMI-1640 medium (GibcoBRL, Gaithersburg, MD, USA) supplemented with $10 \%$ fetal bovine serum (FBS) (HyClone, Thermo Scientific) and $1 \%$ penicillin-streptomycin (Invitrogen) in a humidified chamber with $5 \% \mathrm{CO}_{2}$ at $37^{\circ} \mathrm{C} .1 \times 10^{6}$ cells were seeded per well into a 12 -well plate $(1 \mathrm{ml} /$ well $)$ with glass coverslips.

Ginsenoside Rh2 (purity $98.7 \%$ ) was purchased from Sigma-Aldrich (St. Louis, MO, USA). Stock solution of $\mathrm{Rh} 2$ (final concentration $0.1 \mathrm{M}$ ) was prepared in dimethyl sulfoxide (DMSO), stored at $-20^{\circ} \mathrm{C}$, and diluted with fresh complete medium immediately before use. An equal volume of DMSO (final concentration $<0.1 \%$ ) was added to the controls.

\section{Cell proliferation assay}

A cell survival analysis was performed according to the 3-(4,5-dimethylthiazol-2-yl)-2,5diphenyltetrazolium bromide (MTT) (Cell Titer 96 Aqueous Cell Proliferation Assay kit; Promega, Madison, WI, USA) assay method.

Briefly, cells were plated at $1 \times 10^{5}$ cells per well of the 96-well plate with $\mathrm{Rh} 2$ and $10 \mu \mathrm{l}$ of $4 \mathrm{mg} / \mathrm{ml}$ MTT solution was added to each well. The cells were subsequently incubated for $4 \mathrm{~h}$ in the dark. The absorbance was measured in a microplate reader at $490 \mathrm{~nm}$, and the results were expressed as a percentage of the control.

\section{TUNEL assay}

The terminal deoxynucleotidyl transferase mediated digoxigenin-dUTP-biotin nick-end labeling (TUNEL) assay using the In Situ Cell Death Detection Kit (Roche, Penzberg, Germany) was used to confirm apoptosis by demonstrating apoptotic bodies in SKOV3. Briefly, cells were fixed with $4 \%$ formaldehyde and incubated at room temperature for $40 \mathrm{~min}$. This was followed by several rinses in PBS and permeabilization in $0.2 \%$ Triton X-100 solution on ice for $5 \mathrm{~min}$. Then, $50 \mu \mathrm{l}$ of TUNEL reaction mixture was added on coverslips before being incubated for $60 \mathrm{~min}$ at $37^{\circ} \mathrm{C}$ in a dark humidified chamber. Finally, the coverslips were incubated with 4',6-diamidino-2-phenylindole (DAPI; Sigma) for $20 \mathrm{~min}$ at room temperature and examined with a model LSM 510 confocal microscope (Carl Zeiss, Jena, Germany).

\section{Western blot analysis}

Cells were resuspended in ice-cold cell lysis buffer (Cell Signaling Technology, Beverly, MA, USA) with the Protease Inhibitor Cocktail (complete mini tablet, Roche). Protein concentrations were determined with a BCA assay kit (Pierce, IL, USA) according to the manufacturer's instructions. Protein was separated via $10 \%$ SDS-PAGE, transferred to PVDF membrane, and blocked with $5 \%$ non-fat milk. Membranes were incubated with anti-cleaved caspase-3 (Cell signaling systems), anti-cleaved PARP (Cell signaling systems), 
anti-Bcl-2 (Cell signaling systems) and beta-actin (Sigma) antibodies. Next, the membranes were incubated with HRP-conjugated anti-secondary IgG (Invitrogen) antibody and visualized using Super Signal West Pico Chemiluminescent Substrate (Pierce, IL, USA).

\section{Wound assays to assess cell motility}

A sterile tip was used to wound a cell layer, and the cells were treated with Rh2. The photographs were taken by using a microscope at each time point. The monolayers were scratched with a $200 \mu$ pipette tip and washed with media to remove the detached cells. The wounded areas were then imaged after incubation for an indicated period.

\section{Statistical analyses}

Data are shown as average and standard deviation. When comparing means between two groups, Student's t-test was applied. The level of statistical significance was based on the $p$ values $(\mathrm{p}<0.05)$.

\section{Results}

Effect of ginsenoside-Rh2 on cell proliferation and apoptosis of SKOV3 cells

To examine the effect of $\mathrm{Rh} 2$ on the cell viability of ovarian cancer cells, we treated SKOV3 cells with $30 \mu \mathrm{M}$ and $60 \mu \mathrm{M}$ Rh2 for 0,24 and $48 \mathrm{~h}$ and determined the proportion of surviving cells with an MTT assay. Forty-eight hours of exposure to Rh2 induced a toxic, dose-dependent effect on SKOV3 cells, with a maximal effect of $\sim 50 \%$ inhibition noted at a concentration of $60 \mu \mathrm{M}$. Thus, $60 \mu \mathrm{M}$ was used as the concentration for Rh2 in all further experiments (Fig. 1; $\mathrm{p}<0.05)$.

\section{Ginsenoside-Rh2 induces apoptosis in SKOV3 cells}

The TUNEL assay is a sensitive assay for visualizing DNA damage in single cells resulting from apoptotic signaling cascades (Chen et al. 2013). To assess whether $\mathrm{Rh} 2$ exerts its anti-cancer effects via apoptosis, apoptotic cells were detected using TUNEL assays. We assessed the apoptotic rate of cells treated with $60 \mu \mathrm{M}$ $\mathrm{Rh} 2$ for $24 \mathrm{~h}$ and $48 \mathrm{~h}$. After incubation, cultured cells were fixed and stained for TUNEL along with DAPI. Confocal microscopy was used to compare the numbers of apoptotic cells in the groups cultured with and without Rh2. The number of apoptotic cells significantly increased in the SKOV3 cells treated with $\mathrm{Rh} 2$ in a time- dependent manner, as compared to the control group (Fig. 2).

Caspase-3 activation is the key event in apoptotic cell death. To further evaluate the apoptotic mechanism of $\mathrm{Rh} 2$, we determined the levels of cleaved caspase-3, cleaved PARP, and Bcl-2, an important antiapoptotic protein, by western blot analysis. The levels of cleaved caspase- 3 and cleaved PARP were significantly higher in SKOV3 cells treated with $60 \mu \mathrm{M}$ Rh2 for $48 \mathrm{~h}$ compared to control cells. Furthermore, the Bcl-2 level was significantly decreased in SKOV3 cells treated with $60 \mu \mathrm{M}$ in a time-dependent manner (Fig. 3).

\section{Ginsenoside-Rh2 affects SKOV3 cell mobility}

To further verify that Rh2 blocked epithelialmesenchymal transition (EMT), cell mobility was evaluated with migration assays. As shown in Figures 4A and 4B, $\mathrm{Rh} 2$ treatment significantly inhibited cell mobility and migration. Taken together, our findings strongly indicate that Rh2 is capable of reversing EMTinduced changes in cell mobility, underscoring its potential function as an inhibitor of EMT-mediated cancer metastasis.

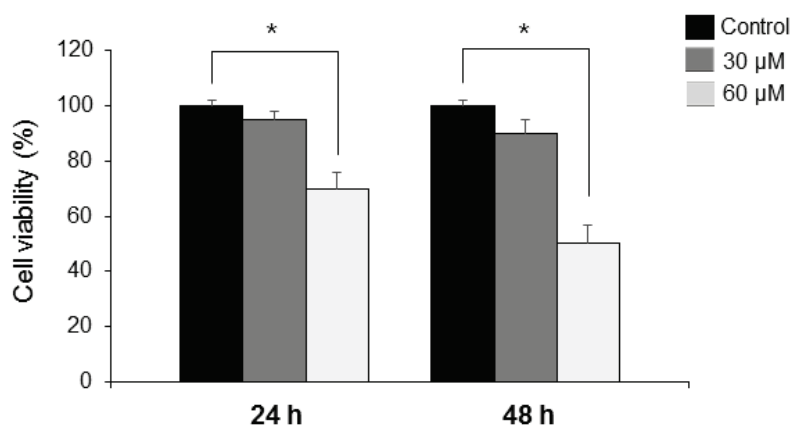

Fig. 1. Effects of Rh2 on viability and apoptosis in SKOV3 cells. Cells were seeded in 96-well plates and treated with various concentrations of Rh2, and cell viability was determined with the MTT assay. The values are calculated relative to the control group $(0 \mu \mathrm{M} R 2)$. The results are shown as mean $\pm \mathrm{SD}$ and are representative of three independent experiments. $* p<0.05$ versus the control group.

\section{Discussion}

In this study, we demonstrated the timedependent development of apoptosis changes in SKOV3 ovarian cancer cells following exposure to ginsenoside$\mathrm{Rh} 2$. Rh2 was found to induce significant apoptotic death of ovarian cancer cells using a TUNEL assay. Furthermore, we showed that the Rh2-induced apoptosis involves activation of caspase- 3 and PARP, and the 
treatment with specific inhibitors of Bcl-2 significantly induced the Rh2-induced cell apoptotic effects. Thus, our results demonstrated that the Rh2-induced apoptosis mechanism occurs through a mitochondria-dependent response. Recent studies have demonstrated the anticancer effect of ginsenoside for many types of cancer. We further found that Rh2 is significantly more potent at inducing cell death in ovarian cancer cells compared to Rg3 (data not shown). These results indicate that Rh2 may be a potent anticancer agent.
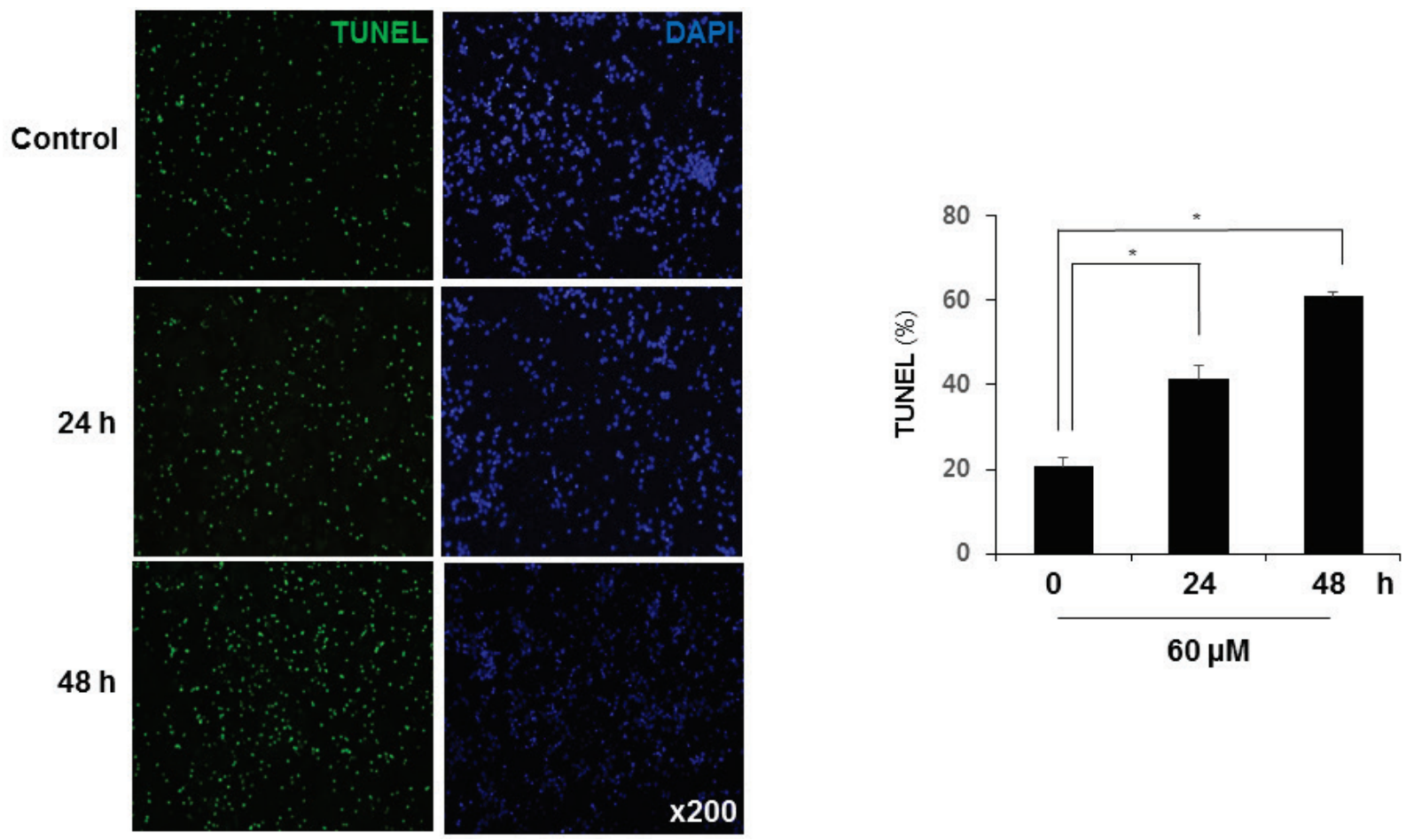

Fig. 2. Rh2 induces apoptosis in SKOV3 cells. Cells were treated with Rh2 and subsequently stained with TUNEL and DAPI. After treatment, the number of apoptotic cells was determined with the TUNEL assay. The TUNEL assay is representative of three independent experiments with similar results.

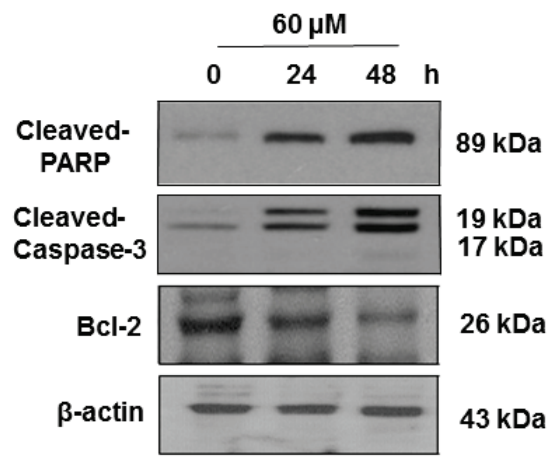

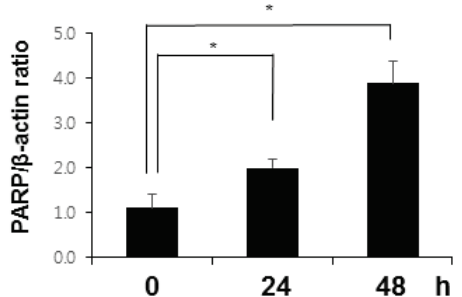
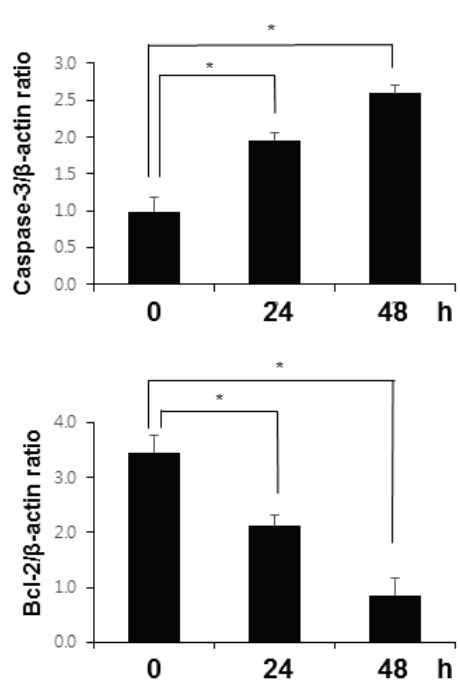

Fig. 3. The level of cleaved caspse- 3 was significantly higher in SKOV3 cells. SKOV3 cells were analyzed for cleaved-caspase-3, and $\mathrm{BCl}-2$ expression by western blotting after treatment with Rh2. The western blots are representative of three independent experiments with similar results. 


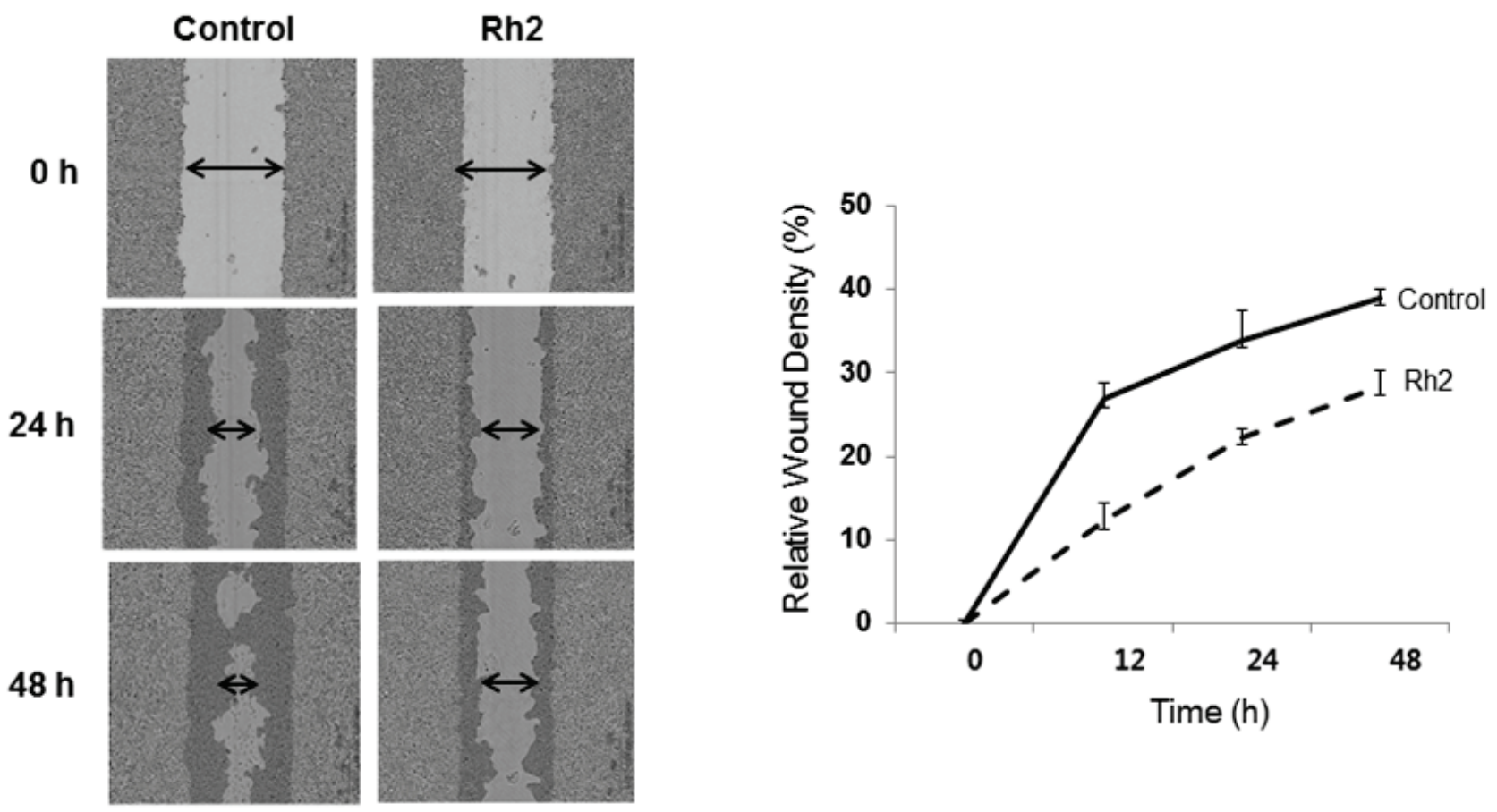

Fig. 4. Rh2 inhibited the mobility of SKOV3 cells. Cell mobility detected by a migration assay. Cells were incubated in media without $\mathrm{Rh} 2$, followed by scratching the confluent cell layer and exposing the cells to Rh2. The closure of the scratch was monitored and photographs were shown at $24 \mathrm{~h}$ and $48 \mathrm{~h}$. All of the experiments were carried out in triplicate.

Ginsenosides can be classified into Rg1, Rg3, $\mathrm{Rh} 1, \mathrm{Rh} 2$, and other components. Anticancer activities tend to increase with decrease of the number of sugar moieties in a ginsenoside molecule. Although the underlying mechanisms are still poorly defined, $\mathrm{Rh} 2$ has been shown to inhibit the growth of a number of types of human cancer cells (Popovich and Kitts 2004, Wu et al. 2011). Rg3 and $\mathrm{Rh} 2$ are the main components in ginsenosides, which have shown potent anti-proliferative effects on cancer cells. $\mathrm{Rh} 2$, with one sugar residue, has shown 5- to 15-fold relatively stronger anti-apoptotic effects than $\mathrm{Rg} 3$, with two sugar residues (Nag et al. 2012, Yu et al. 2007, Wang et al. 2007). Rh2 may inhibit carcinoma cell growth through mediating coordinated autophagy, $\beta$-catenin signaling and inhibiting MMP13 (Guan et al. 2015, Kumar et al. 2016, Yang et al. 2016).

Moreover, the EMT is an important process in cancer metastasis, in which epithelial cells lose their properties resulting in migration to other sites. Therefore, we investigated the effects of Rh2 on EMT in ovarian cancer cells. The migration assays showed that Rh2 inhibited the cell mobility of SKOV3 cells. The results from the present study suggest that the anticancer actions of Rh2 are associated with its effects on the EMT. The EMT is regulated by transcription factors, including Snail, Twist, and ZEB. Induced EMT can promote the metastasis of cancers via several signaling pathways such as TGF- $\beta$, MAPK, and NF- $\mathrm{kB}$ signaling (Liu et al. 2015, Hou et al. 2014). Furthermore, given that EMT promotes motility, it can promote cancer progression (Ahmed et al. 2010). We demonstrated that the $\mathrm{Rh} 2$-induced suppression of EMT may contribute to the observed increases in cell-cell interactions and decreased capacity for motility in ovarian cancer cells. Thus, reversing the EMT may be an alternative strategy for cancer therapy.

In conclusion, ginsenoside-Rh2 was shown to suppress the growth of SKOV3 ovarian cancer cells in vitro, which is associated with inductions of apoptotic cell death. Therefore, Rh2 appears to be a useful natural material for enhancing the apoptosis of cancer cells. Furthermore, Rh2 was found to influence cell mobility in SKOV3 cells. Considering these properties, Rh2 appears to be a promising natural anti-cancer agent, which warrants further research for potential clinical application.

\section{Conflict of Interest}

There is no conflict of interest.

\section{Acknowledgements}

This study was supported by grants from the Far East University. 


\section{References}

AHMED N, ABUBAKER K, FINDLAY J, QUINN M: Epithelial mesenchymal transition and cancer stem cell-like phenotypes facilitate chemoresistance in recurrent ovarian cancer. Curr Cancer Drug Targets 10: 268-278, 2010.

CHEN G, GONG M, YAN M, ZHANG X: Sevoflurane induces endoplasmic reticulum stress mediated apoptosis in hippocampal neurons of aging rats. PLoS One 8: e57870, 2013.

CHO KR, SHIH IEM: Ovarian cancer. Annu Rev Pathol 4: 287-313, 2009.

CHUNG JG, YANG JS, HUANG LJ, LEE FY, TENG CM, TSAI SC, LIN KL, WANG SF, KUO SC: Proteomic approach to studying the cytotoxicity of YC-1 on U937 leukemia cells and antileukemia activity in orthotopic model of leukemia mice. Proteomics 7: 3305-3317, 2007.

DA ROCHA AB, LOPES RM, SCHWARTSMANN G: Natural products in anticancer therapy. Curr Opin Pharmacol 1: 364-369, 2001.

FULDAS KM, DEBATI KM: Extrinsic versus intrinsic apoptosis pathways in anticancer chemotherapy. Oncogene 25: 4798-4811, 2006.

GREEN DR, REED JC: Mitochondria and apoptosis. Science 281: 1309-1312, 1998.

GUAN N, HUO X, ZHANG Z, ZHANG S, LUO J, GUO W: Ginsenoside Rh2 inhibits metastasis of glioblastoma multiforme through Akt-regulated MMP13. Tumour Biol 36: 6789-6795, 2015.

HOU CH, LIN FL, HOU SM, LIU JF: Cyr61 promotes epithelial-mesenchymal transition and tumor metastasis of osteosarcoma by Raf-1/MEK/ERK/Elk-1/TWIST-1 signaling pathway. Mol Cancer 13: 236, 2014.

JACOBSON MD, WEIL M, RAFF MC: Programmed cell death in animal development. Cell 88: 347-354, 1997.

JANG JH, CHO YC, KIM KH, LEE KS, LEE J, KIM DE, PARK JS, JANG BC, KIM S, KWON TK, PARK JW: BAI, a novel Cdk inhibitor, enhances farnesyltransferase inhibitor LB42708-mediated apoptosis in renal carcinoma cells through the down regulation of Bcl-2 and c-FLIP (L). Int J Oncol 45: 1680-1690, 2014.

KELLOFF GJ, CROWELL JA, STEELE VE, LUBET RA, MALONE WA, BOONE CW, KOPELOVICH L, HAWK ET, LIEBERMAN R, LAWRENCE JA, ALI I, VINER JL, SIGMAN CC: Progress in cancer chemoprevention: development of diet-derived chemopreventive agents. J Nutr 130: 467S-471S, 2000.

KUMAR RV, OH TW, PARK YK: Anti-inflammatory effects of ginsenoside-Rh2 inhibits LPS-induced activation of microglia and overproduction of inflammatory mediators via modulation of TGF- $\beta 1 /$ Smad pathway. Neurochem Res 41: 951-957, 2016.

LAMKANFI M, FESTJENS N, DECLERCQ W, VANDEN BERGHE T, VANENABEELE P: Caspases in cell survival, proliferation and differentiation. Cell Death Differ 14: 44-55, 2007.

LAVRIK LN, GOLK A, KRAMMER PH: Caspases: pharmacological manipulation of cell death. J Clin Invest 115: 2665-2672, 2005.

LIU X, KIM CN, YANG J, JEMMERSON J, WANG X: Induction of apoptotic program in cell-free extracts: requirement for dATP and cyto c. Cell 86: 147-157, 1996.

LIUS, JIN K, HUI Y, FU J, JIE C, FENG S, REISMAN D, WANG Q, FAN D, SUKUMAR S, CHEN H: HOXB7 promotes malignant progression by activating the TGF-beta signaling pathway. Cancer Res $\mathbf{7 5}$ : 709-719, 2015.

LU CC, YANG JS, CHIANG JH, HOUR MJ, LIN KI, LIN JJ, HUANG WW, TSUZUK M, LEE TH, CHUNG JG: Novel quinazolinone MJ-29 triggers endoplasmic reticulum stress and intrinsic apoptosis in murine leukemia WEHI-3 cells and inhibits leukemic mice. PLoS One 7: e36831, 2012.

LUO X, WANG CZ, CHEN J, SONG WZ, LUO J, TANG N, HE BC, KANG Q, WANG Y, DU W, HE TC, YUAN CS: Characterization of gene expression regulated by American ginseng and ginsenoside $\mathrm{Rg} 3$ in human colorectal cancer cells. Int J Oncol 32: 975-983, 2008.

MANN J: Natural products in cancer chemotherapy: past, present and future. Nat Rev Cancer 2: 143-148, 2002.

MURPH LL, RICE JA, ZONG W: Ginsenosides Rc and Rh2 inhibit MCF-7 cell proliferation through distinctly different mechanisms. Mol Biol Cell 12: 764, 2001. 
NAG SA, QIN JJ, WANG W, WANG MH, WANG H, ZHANG R: Ginsenosides as anticancer agents: in vitro and in vivo activities, structure-activity relationships, and molecular mechanisms of action. Front Pharmacol 28: 25, 2012.

NAGAT S: Apoptosis by death factor. Cell 88: 355-365, 1997.

POPOVICHD G, KITTSD D: Ginsenosides 20(S)-protopanaxadiol and Rh2 reduce cell proliferation and increase sub-G1 cells in two cultured intestinal cell lines, Int-407 and Caco-2. Can J Physiol Pharmacol 82: 183-190, 2004.

SANJIV K, SU L, SUMAN S, KAKADIYA R, LAI TC, WANG HY, HSIAO M, LEE TC: The novel DNA alkylating agent BO-1090 suppresses the growth of human oral cavity cancer in xenografted and orthotopic mouse models. Int J Cancer 130: 1440-1450, 2012.

SALVESEN GS, DIXIT VM: Caspases: intracellular signaling by proteolysis. Cell 91: 443-446, 1997.

SUN Q, SAKAIDA T, YUE W, GOLLIN SM, YU J: Chemosensitization of head and neck cancer cells by PUMA. Mol Cancer Ther 6: 3180-3188, 2007.

SWISHER EM, TANIGUCHI T, KARLAN BY: Molecular scores to predict ovarian cancer outcomes: a worthy goal, but not ready for prime time. J Natl Cancer Inst 104: 642-645, 2012.

TAATJES DJ, SOBEL BE, BUDD RC: Morphological and cytochemical determination of cell death by apoptosis. Histochem Cell Biol 129: 33-43, 2008.

VAUX DL, KORSMEYER SJ: Cell death in development. Cell 96: 245-254, 1999.

WANG CZ, YUAN CS: Potential role of ginseng in the treatment of colorectal cancer. Am J Chin Med 36: 1019-1028, 2008.

WANG CZ, AUNG HH, NI M, WU JA, TONG R, WICKS S, HE TC, YUAN CS: Red American ginseng: ginsenoside constituents and antiproliferative activities of heat-processed Panax quinquefolius roots. Planta Med 73: 669-674, 2007.

WANG W, ZHAO Y, RAYBURN ER, HILL DL, WANG H, ZHANG R: In vitro anti-cancer activity and structureactivity relationships of natural products isolated from fruits of Panax ginseng. Cancer Chemother Pharmacol 59: 589-601, 2007.

WU N, WU GC, HU R, LI M, FENG H: Ginsenoside Rh2 inhibits glioma cell proliferation by targeting microRNA-128. Acta Pharmacol Sin 32: 345-353, 2011.

YANG Z, ZHAO T, LIU H, ZHANG L: Ginsenoside Rh2 inhibits hepatocellular carcinoma through $\beta$-catenin and autophagy. Sci Rep 19: 19383, 2016.

YU Y, ZHOU Q, HANG Y, BU X, JIA W: Antiestrogenic effect of 20S-protopanaxadiol and its synergy with tamoxifen on breast cancer cells. Cancer 109: 2374-2382, 2007. 